\title{
BEHAVIOURAL MANAGEMENT TECHNIQUES IN PEDIATRIC CLINIC
}

\section{J Chandrapooja \& Kathiravan Selvarasu}

Saveetha Dental College, Poonamalle High Road, Velappanchavadi Chennai-660077 Oral Maxillofacial Surgeon, Saveetha Dental College, 162, Poonamallee High Road, Chennai, Tamilnadu-600077

*Corresponding Author Email: jchandrapooja@gmail.com

\begin{abstract}
The child management behaviour in paediatric clinic is the way by which the dental health care team effectively and efficiently performs treatment for a child. Management of children in the paediatric clinic is complex balancing act involving the child, parent and the dentist. To provide dental care for children good communication skills are necessary. Anxiety is a recognised personality trail, and there are some other factors which were found to increase the subsistence of behaviour problems during dental procedure. Behaviour management is widely agreed to be a key factor supplying dental care for children. Certainly, if a child's behaviour in the dental surgery/office cannot be managed then it is not easy to hold out any dental care that is needed.
\end{abstract}

\section{KEY WORDS}

child management behaviour, tell show do.

\section{INTRODUCTION}

The child management behaviour in paediatric clinic is the way by which the dental health care team effectively and efficiently performs treatment for a child [1]. The aim is to establish a positive dental attitude as it is important for all behaviour management techniques [2] . It is not only about the behaviour necessary to complete a given procedure, but also creates a long-term interest on the patient's attitude for ongoing prevention. The dentist must inculcate a rapport based on trust with the child and their parent complaints allowing proper treatment to occur and this is called the TREATMENT ALLIANCE [3]. Children with dental anxiety may refuse treatment, which can lead to dental emergencies. Behavioural management is an essential skill and should be acquired by all members of a dental team treating children. Dental surgery staff should be relaxed, welcoming and friendly. Make the child the centre of attention and smile. Use age-appropriate language and avoid the use of jargon. Decide who will talk to the child and when, as he/she may only be able to listen to one person at a time. Avoid non-dental conversations with colleagues during procedures. [4]

\section{MANAGEMENT OF CHILDREN}

Management of children in the paediatric clinic is complex balancing act involving the child, parent and the dentist. To provide dental care for children good communication skills are necessary. A considerable percentage of children do not co-operate in the dental chair, causing an obstruction to delivery of quality dental care. This gives rise to behaviour management techniques or alternatives to communicative management. Behaviour management of the child patient is an intrinsic component of paediatric dental practice. Parents and careers may also play an important part in reduce the child's anxiety, allowing the dentist to perform the treatment and manage them. [5]

\section{Goals of behaviour management}

* Communication maintenance

* Reduction of fear and anxiety.

* Correct inappropriate behaviour. 
* Elicit behaviour consistent with the need for successful completion of treatment.

\section{FACTORS INFLUENCING CHILD BEHAVIOR}

Anxiety is a recognised personality trail, and there are some other factors which were found to increase the subsistence of behaviour problems during dental procedure.

MEDICAL HISTORY: Children who had experienced a negative aspect associated with medical treatment may be more anxious about the dental procedures, just like that, fear carried from previous unhappy dental visits may also be related to poor behaviour at upcoming visits. The dentist should include questions about previous medical treatments while taking the medical history and also the child's response to them. $[6,7]$

\section{PARENTAL INFLUENCE}

Parent's anxiety had a major influence on their child's behaviour, particularly if they had earlier negative dental incidents. An anxious or afraid parent may influence a child's behaviour pessimistically. Educating the parent prior to the child's first dental visit is important. There are office procedures like the early telephone call, go after by sending office information and a temptation to visit the office website or even an office "pre-visit," may be supportive in reducing parental anxiety.

Parenting styles have changed in recent years. Dentists are faced with challenges from the rising number of children who a lot of times are illequipped, the skills and self-discipline necessary to deal with novel experiences in the dental clinic. Commonly, parental expectations for the child's behaviour (e.g., no tears) are impracticable. Some parents may even attempt to dictate treatment, although their knowledge of the procedure is lacking. Parents will also be able to predict the associated behaviour of their children accurately.

Practitioners have the same opinion that a good communication is important between the parent, dentist, and parent in building faith and assurance. Practitioners also assure in the fact that valuable communication among the dentist and the child is dominant and requires understanding on both sides. Most kids react positively when their parent is there beside them during the treatment. Rarely, the presence of a parent has a negative consequence on the communication between the child and the dentist. Each clinician has responsible to establish the communication and support methods that optimize the treatment setting, identifying their own skills, the capability of the particular child, and the wishes of the parent involved. $[8,9]$

\section{FOR CO-OPERATIVE CHILDREN}

TYPES OF CHILD BEHAVIOURAL MANAGEMENT TECHNIQUES

-tell show do

-Positive reinforcement

-Voice control

-Distraction

-Euphemism

-Live modelling

-Nonverbal communication

-Systematic desensitization

\section{TELL SHOW DO}

This method is extensively use to familiarise a new procedure to the patient [10]. This is the verbal explanations of procedures in the way the child could understand (tell); presentation of the visual, auditory, olfactory and touching aspects of the procedure in a carefully done without threatening (show) and then, without deviating from explanation and demonstration, the procedure has to be done (do). The tell-show-do technique is used with verbal and non-verbal communication skills and positive reinforcement. Other measures will be needed depending on whether the child has communication problems or disorders. This technique has been an effective way for reducing previously formed anxiety in the child patient [11]. In the tell phase the dentist gives an explanation about the procedure depending upon the age of the patients. The show phase is used to illustrate the procedure, example demonstrating with a slow hand piece on a finger.

\section{POSITIVE REINFORCEMENT AND BEHAVIORAL SHAPING}

Positive reinforcement is an effective technique for desired behaviours and strengthens the repeated occurrence of those behaviours. All members of the dental team include social reinforce such as positive voice modulation, facial expression, verbal praise and 
appropriate physical demonstrations of affection. Some of the non-social reinforces are toys and tokens. As most of the dental procedures require quite complex behaviours and actions, the patients are to be explained and learned, about them. For children this should be explained in small clear steps. This is called as shaping process. It consists of a well-defined set of steps towards perfect and complete behaviour [14]. By selective reinforcement this is most easily achieved. When the behaviour pattern is strengthened it increases the being displayed again in the future which is called as reinforcements [15]. Anything that the child finds pleasant can act as positive reinforcers such as stickers and fun labels are used when the appointment was successful. A child centred, emotional response giving specific praise such as," Good girl ", " I like the way you have kept your mouth open". But the latter is shown to be more effective than a general comment previous one. [16] The technique is useful only for all patients who can communicate.

\section{VOICE CONTROL}

The pace, tone and alteration of voice volume, can influence the child's behaviour. This technique is ineffective for children with severe hearing impairments. Young children often respond to the tone of voice more when compared to the actual words. These all techniques aim to improve attention and compliance as well as to establish control over the child to an extent. However, it is widely used by dentists but may not be acceptable to all parents or clinicians [12].

The technique is useful for communicative children who are inattentive and is not appropriate for children who are too young to understand or with emotional impairment. This technique has been shown to decrease undisciplined behaviour without producing long-term negative effects [13].

\section{DISTRACTION}

This technique diverts the child's attention from what may think as an unpleasant procedure. This can be done through talking, asking the parent to play with the child, using headphones to play music or allowing the child to watch a DVD or some cartoons. This approach aims to shift the patient's attention from the dental procedure which can be potentially unpleasant to some other situation. Cartoons have been shown to reduce disruptive behaviours in children when combined with reinforcement, that is when children knew the cartoon would be switched off if they did not behave 18]. It has been found that audio tapes may be even more effective than other modes of distractions [19]. The dentist distracts with words while applying topical paste and administering local anaesthetic. Short term distractors such as diverting the attention by pulling the lip as a local anaesthetic is very useful. The technique is useful for all patients who can verbally communicate. There are no contraindications.

\section{LIVE MODELLING TECHNIQUE}

In this technique the doctor makes the child to observe one or more individuals who demonstrate positive behaviour in a particular situation. Models like a parent or a sibling can be used for this modelling. If a live model is not available filmed models like videos $[20,21]$ or posters can also be used for demonstrating.

The technique is based on the psychological principle that people learn about their environment by observing others' behaviour, by using a model, which exhibits appropriate behaviour in the dental environment. This may demonstrate appropriate behaviour via a third person, and decrease anxiety by showing a positive outcome to a procedure. For best effects models should be the same age and should exhibit appropriate behaviour that of target child. They should also be shown entering and leaving the surgery [22].

\section{NON VERBAL COMMUNICATION}

Types

-body language
-smiling
-eye contact
-expression of feeling without speaking
-by touching the child
-giving him a pat
-showing concern
-giving him a hug

Posture and facial expression and appropriate contact, are used for reinforcement and guidance of behaviour. This technique is appropriate for children 
with hearing impairments. Establish contact to calm the child; however, some children have tactile defensiveness startle reflexes.

\section{SYSTEMATIC DESENSITISATION}

This technique focuses on individuals with specific fears or phobias to overcome them by repeated contacts. A hierarchy of fear-producing stimuli is constructed, and the patient is exposed to them in an ordered manner, starting with the stimulus posing the lowest threat. In dental terms, the use of local anaesthetic is usually related to a specific procedure which creates fear. The patient is asked to relax first, and in this state he is exposed to each of the stimuli in the hierarchy in turn, and progressing to the next when they feel able. Several relaxation sessions with a psychologist or dentist who has received training in relaxation or hypnosis techniques may be required for true phobias. [2] A 9 hour long sessions with a therapist is required [23]. However, a similar approach can be used for children who have had a negative experience in the past [24]. The technique is useful for a child who can clearly identify their fear and who can verbally communicate.

\section{EUPHEMISM}

Choices of words, which is used by the dentist ot staff influence the emotional status of the patient. Therefore, the use of euphemism or reframing is very important while addressing to the patient.

1. Anaesthetic solution is referred to as water to put the teeth to sleep

2. Caries is referred to as a tooth bug

3. Rubber dam as a rain coat

4. Radiograph as tooth picture

\section{FOR HYPERACTIVE CHILDREN}

Majority of the children can be managed effectively using the techniques which are listed above. However, children, who occasionally present with behavioural changes like being hyperactive will need more advanced techniques.

These children often cannot cooperate due to lack of psychological or emotional maturity and/or mental, physical or medical disability. The protective stabilization, sedation and general anaesthesia are some of the advanced behaviour guidance techniques are used and are taught in advanced paediatric dental programmes.

\section{NITROUS OXIDE OXYGEN INHALATION}

It is a safe, secure and effective, useful [25] behaviour management technique.

Use Nitrous Oxide Oxygen sedation:

* Patients who are anxious.

* As an adjunct to local anaesthesia.

* In a patient whose gag reflexes interfere with dental care.

* If able to obtain written informed.

\section{PHYSICAL RESTRAIN}

It includes partial or complete immobilization with dentist, parent or devices to protect the patient from injury during dental treatment. Prior to the procedure informed consent must be obtained from the patient. Various types of restraints

For the body

* Pedi wrap

* Papoose board

* Sheets

* Beanbag with straps

* Towels and tapes

For the Head

* Head positioner

* Mouth blocks

* Banded tongue blades

* Beanbag with straps

* Mouth props

Hand-Over-Mouth Technique

It is another behaviour management technique that is controversial and may be offensive to some parents. The child is made to put his hand over his mouth and behavioural expectations are explained. The hand is removed, depending on the behaviour of the child. Since there are more potential legal liabilities involving this technique it's use is discouraged except for senior clinicians and paediatric dental consultants. Parent consent is more important, and the techniques should never be used on the children too young to understand or with intellectual or emotional impairments [26-28].

\section{CONSCIOUS SEDATION}

Sedation is an important technique to guide a child's behaviour during dental treatment. Medications which are being used, help to increase cooperation 
and to reduce anxiety or discomfort associated with dental procedures. Sedative medications cause most children to become relaxed and drowsy. Unlike general anaesthesia, sedation is not intended to make a patient unconscious or unresponsive.

Conscious sedation technique is indicated for

* Patients who are healthy at the time of the appointment.

* Patients who cannot cooperate due to disability or immaturity.

* Patients who need care is consistently with the risks of sedation and whose care can be completed in one or two appointments.

\section{GENERAL ANASTHESIA}

If toddlers are often very frightened of the dentist this technique can be used. Even if they do not actually feel pain, sounds they hear from the dental drill and the feeling of pressure that they feel, can make them go into hysterics. Also some children will have a lot of dental works that has to be completed on multiple teeth. So, it is often best to put the child completely to sleep and finish of all the treatment in a single, stress-free visit. Dentists hire an Anaesthesiologist to come to the office regularly, to provide the safest and most comfortable way to treat young children with a lot of decay. Afterwards, the anaesthesiologist will give the right dosage of drugs to completely put the child to sleep. Once the child is completely sleeping, the child's breathing and vital signs are monitored by the anaesthesiologist, while the paediatric dentist provides all necessary treatment.

Use general anaesthesia in

* Patients with physical and mental abnormalities.

* Extremely uncooperative child with extensive dental needs.

* Patients with dental needs who otherwise would not get dental care

Prior to application of GA, proper documentation which address the foundation for the use of $G A$, informed authority, instructions provided to the parent, dietary precautions and pre-operative health evaluation [29].

\section{CONCLUSION}

Behaviour management is widely agreed to be a key factor supplying dental care for children. Certainly, if a child's behaviour in the dental surgery/office cannot be managed then it is not easy to hold out any dental care that is needed. A wide variety of behavioural management techniques are available to paediatric dentists which must be used as appropriate taking into account cultural, philosophical and legal requirements in the country of dental practice of every dentist concerned with dental care of children, solely for the benefits of the child. This also related with an important thing called treatment alliance, once if a child or parents are comfortable with the treatment of clinician then they will keep on consulting the same clinician.

\section{REFERENCES}

[1] Wright, G. Z (1975) BEHAVIORAL management in dentistry for Children.W.B.Saundres Company.

[2] Wright,G.Z, starkly,P.E and Gardner,D.E (1987)child management in dentistry, Oxford ; wright.

[3] Frankl, S.H., Shiere,F.R and Fogels ,H.R.(1962)should the parent remain within the dental operatory? J Dent child 29: 150-163.

[4] Pubmed,Behavior management of an anxious child : Gupta.A, Marya.C.M , Bhatia.H.P, Dahiya.V

[5] Freeman,R.(1999)The case for mother in the surgery. Brit Dent J186: 610-613.

[6] Wright, G.Z. and Alpern, G.D. (1971) variables influencing children's co-operative Behavior at first visit. J Dent child, 23: 124-128

[7] Bailey, P.M., Talbot.M. and Taylor. P.P (1973) A comparison of maternal anxiety and anxiety levels manifested in the child patient. J Dent child 40:277-284

[8] Johnson, R.and Baldwin, D.C.Jr (1969) Maternal anxiety and child behavior . J Dent child 36:87-92

[9] Johnson, R. and Baldwin, D.C. Jr (1968) Relationship of maternal anxiety to the Behavior of Young chil undergoing dental extraction. J Dent Res 47: 801-805

[10] Mc Knight-Hanes, C., Myers, D.R., Dushku, J.C. and all (1993) The use of Behavior management techniques by dentist across practitioner type,age,and geographic region. Pediatric Dent 15:267-271

[11] Carson, P. and Freeman, R. (1998) Tell show do: reducing anticipatory anxiety in emergency pediatric dental patients. Int J Health prom and Education 36: 8790. 
[12] Greenbaum, P.E., Turner, C. and Cook, 3rd. E.W and all (1990) Dentist's voice control: effects on children's disruptive behaviour. Health psychology 9: 546-558

[13] Roberts, J.F. (1995) How important are techniques? The empathic approach to working with the children. J Dent child 62: 38-43.

[14] Lencher, V. And Wright, G.Z., (1975) Nonpharmacotherapeutic approaches to Behavior management. In: Wright, G.Z.,;Ed) Behavior management in dentistry for children. Philadelphia, Saunders.

[15] Satwell, R., Simon. J.F. and simeonsson, R. (1974) The effects of five preparatory methods upon children Behavior during the first dental visit. J Dent child 41 : 367-375.

[16] Weinstein, P. and Bathan,J.(1988) The challenge of fearful and phobic children. In: Dental phobias and anxiety. Den Clin N Amer .

[17] Johnson, R. and Machen, J.B. (1973) Behavior modification techniques and maternal anxiety. J Dent child 40:272-276

[18] Ingersoll, B.D., Nash, D., Blount, R. and Gamber,C. (1984) Disraction and contingent reinforcement with pediatric dental patients. J Dent child 51:203-207.

[19] Ingersoll, B.D., Nash, D., Blount, R. and Gamber,C. (1984) The use of contingent audio taped material with pediatric dental patients. J Am Dent Assoc 109: 717-719.
[20] Machen, J.B. and Johnson, R. (1974) Desensitization model learning, and the dental Behavior of children, J Dent Res 53:83

[21] Melamed, B.G., Weinstein,D., Hawes, R. and all (1975) Reduction of fear - related dental management problems with use of filmed modelling, J Am Dent Assoc 90:822-826.

[22] Ingersoll, B.D., Nash, D., Blount, R. and Gamber,C.(1984) Disraction and contingent reinforcement with pediatric dental patients. J Dent child 51:203-207.

[23] Gale, E.H.and Ayer, W.A. (1969) Treatment of dental phobias. J Am Dent Assoc 8:130-134.

[24] Fayle, E.H. and Crawford, P.J.M. (1997) Making dental treatment acceptable children. Dental profile September: 18-22.

[25] American Academy of Pediatric Dentistry. Guideline on use of nitrous oxide for pediatric. Pediatric Dent 2011; 33:181-4.

[26] Fayle S, Crawford PJ. Making dental treatment acceptable to children. Dent Profile 1997; 41:178-82.

[27] American Academy of Pediatric Dentistry Guidelines for Behavior management. Pediatric Debt 1998; 20:27 -32.

[28] Levitas TC. HOME - hand over mouth exercise. ASDC J Dent child 1974; 41:178-82.

[29] American Academy of Pediatric Dentistry. Guideline on use of anaesthesia personnel in administration of officebased deep sedation/ general anaesthesia to the Pediatric dental patient. Pediatric Dent 2011; 33:202-4. 